\title{
TIEMPO Y ESPACIO PARA LA REGENERACIÓN DE VEGETALES EN TRES LOCALIDADES DE LA PROVINCIA DE CHACO, ARGENTINA
}

\author{
MYRIAM FERNANDA PERRET ${ }^{1}$ \\ UNIVERSIDAD NACIONAL DE MISIONES / CONICET, ARGENTINA
}

\begin{abstract}
RESUMEN: En esta ocasión analizamos el modo en que se relacionan humanos y no-humanos, en particular, atendemos a las relaciones entre artesanas (de los pueblos Wichi y Qom), trabajadores o técnicos de programas de desarrollo rural, dueños no-humanos y vegetales que proveen fibras con las que aquellas tejen. Los trabajos tejidos se destinan, en su mayoría, al intercambio mercantil.

El trabajo se basa en la tesis de doctorado de la autora. Se trabajó con el método etnográfico de investigación. La recolección de la información, en alternancia con periodos de sistematización y reflexión sobre el material recolectado, transcurrió entre agosto de 2012 y agosto de 2018.

Las relaciones estudiadas aqui se expresan en la siguiente tipificación de vegetales: los que crecen en el monte, cuyo crecimiento requiere que se respete el compuesto ambiente-organismo; los que crecen en el ámbito del hogar, que se cuidan como mascotas para que crezcan y los que se plantan, cuidan, cosechan y guardan las semillas para que crezcan y se reproduzcan.

Dichos vegetales guardan relación con los dueños no-humanos. Las vinculaciones se basan en el encadenamiento necesidad-compasión-don.
\end{abstract}

PALABRAS-CLAVE: Vegetales; Chaco; Domesticación; Regeneración

\begin{abstract}
In this paper we analyze the way in which humans and non-humans are related, in particular, we pay attention to the relationships between artisans (of the Wichi and Qom peoples), workers or technicians of rural development programs, non-human owners and plants that provide fibers with which the artisans weave. The woven works are destined, in their majority, to the mercantile interchange.

The work is based on the doctoral thesis of the author. We worked with the ethnographic research method. The collection of information, in alternation with periods of systematization and reflection on the material collected, elapsed between August 2012 and August 2018.

The relationships studied here are expressed in the following types of plants: those that grow in the forest, whose growth requires respecting the environment-organism compound; those who grow up at home, who are cared as pets to grow and those that are planted, cared for, harvested and saved the seeds so that they grow and reproduce.

These plants are related to non-human owners. The links are based on the need-compassion-gift chain.
\end{abstract}

KEYWORDS: Vegetables; Chaco; Domestication; Regeneration

\footnotetext{
${ }^{1}$ Investigadora de la Facultad de Humanidades y Ciencias Sociales (Universidad Nacional de Misiones, Argentina) y del Consejo Nacional de Investigaciones Científicas y Técnicas (CONICET). E-mail: myfperret@gmail.com
} 


\section{Introducción}

En esta ocasión analizamos el modo en que se relacionan humanos y no-humanos, en particular, atendemos a las relaciones entre artesanas, trabajadores o técnicos de programas de desarrollo rural, dueños nohumanos y vegetales que proveen fibras con las que aquellas tejen. Los trabajos tejidos se destinan, en su mayoría, al intercambio mercantil.

Las artesanas en cuestión pertenecen a tres colectivos de los pueblos Wichí (familia lingüística Mataco-mataguaya) y Qom (familia lingüística Guaycurú) de las localidades de El Sauzalito, Misión Nueva Pompeya y Fortín Lavalle respectivamente. Estos colectivos se encuentran en relación con trabajadores estatales y de ONGs en el marco de programas de desarrollo rural orientados a potenciar la cualidad mercantil de las artesanías.

Fortín Lavalle, El Sauzalito y Misión Nueva Pompeya se encuentran ubicadas en el departamento General Güemes en el noreste de la Provincia del Chaco (Imagen 1). Fortín Lavalle se encuentra a 263 km de Resistencia (capital de la provincia del Chaco), sobre la ruta provincial $\mathrm{N}^{\circ} 3$ (la pavimentación fue concluida a fines del año 2013), cerca de la confluencia de los ríos Teuco y Bermejito, y es atravesada por el río Guaycurú. Misión Nueva Pompeya dista $480 \mathrm{~km}$ de la capital de Chaco (aproximadamente 300 $\mathrm{km}$ se encuentran asfaltados) y un kilómetro del río Bermejito. $70 \mathrm{~km}$ de tierra separan esta última localidad de El Sauzalito, ubicada sobre la margen derecha del río Teuco.

Las artesanas de los colectivos de Misión Nueva Pompeya y El Sauzalito trabajan principalmente con chaguar o chitsaj (Bromelia hieronymi) y las artesanas del colectivo de Fortín Lavalle trabajan generalmente con palma o lagaxadai (Trithrinax schizophylla). Recolectan del monte dichos vegetales, lo cual se encuentra profundamente ligado al hacer de no-humanos como dueños (por ejemplo, Jwistes -cuidadora del chaguar-y No'ouet -dueño del monte-) y los Arco Iris o Lawo (wichi) o Quemonaxalo (qom). 
Imagen 1: localización de Fortín Lavalle, Misión Nueva Pompeya y El Sauzalito

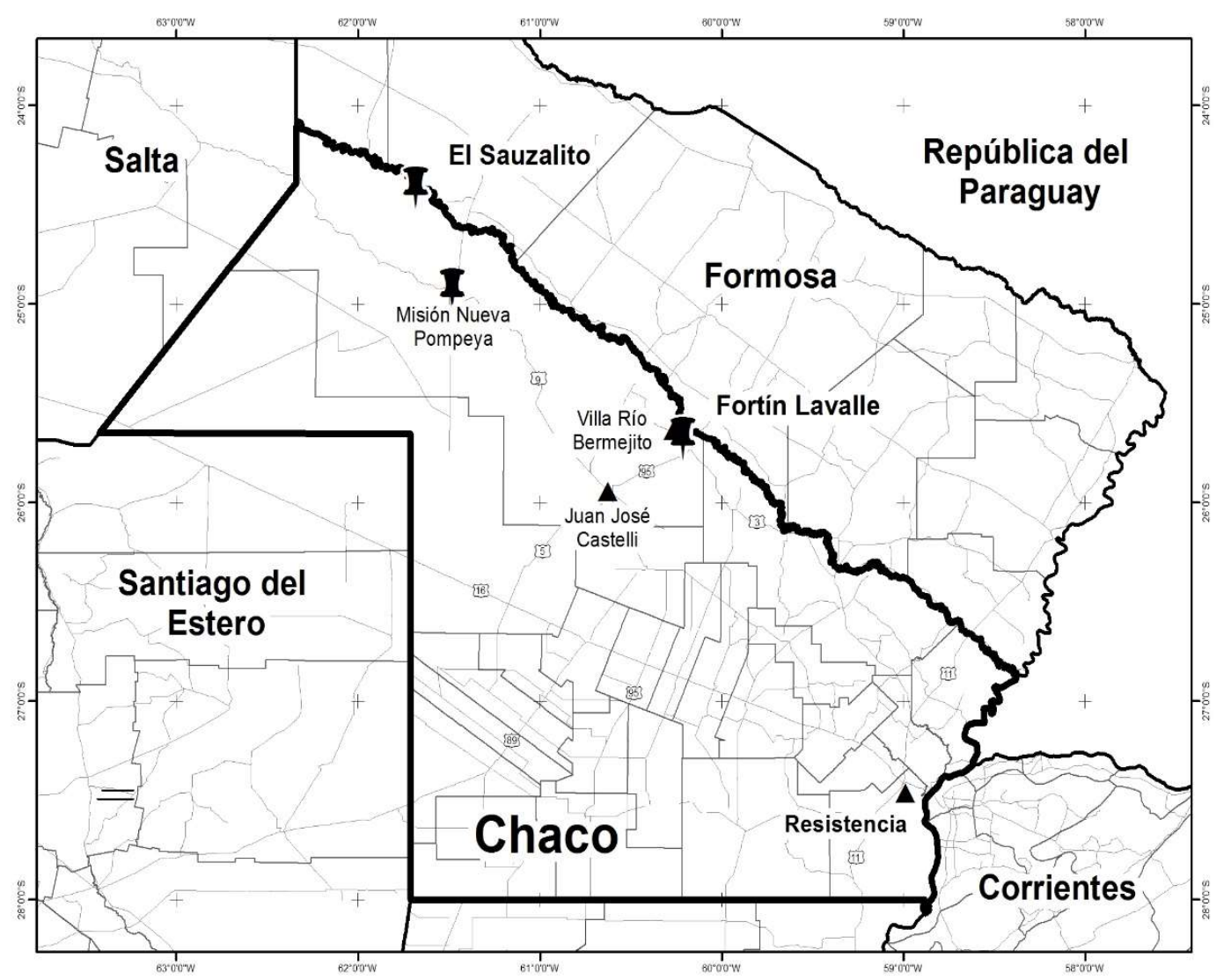

Fuente: Carolina Perret

Primeramente, presentamos la metodología seguida para el desarrollo de este trabajo. A continuación, vemos el modo en que las relaciones entre humanos, dueños no-humanos y Arco Iris influyen en la recolección de chaguar y palma. Luego, atendiendo a la participación de humanos y nohumanos, indagamos en los distintos tipos de relaciones que los humanos entablan con los vegetales. Finalmente, analizamos el lugar que le cabe a las dependencias recíprocas en la regeneración.

\section{Metodología}

Este trabajo está basado en la tesis de doctorado, elaborada por quien escribe, titulada: "La artesanía indígena chaqueña y el mercado: los casos Qom y Wichí de Fortín Lavalle y El Sauzalito".

Trabajamos con el método etnográfico de investigación. Obtuvimos información a partir de las siguientes técnicas: observación participante, 
entrevista etnográfica y documentos informales y oficiales. Alternamos períodos de recolección de información con otros de sistematización, reflexión, producción de monografías y modificación de roles a lo largo de la investigación. Registramos la información, principalmente, por escrito, aunque en ciertas ocasiones recurrimos a la grabación, la fotografía y el video. La recolección de la información, en alternancia con períodos de sistematización y reflexión sobre el material recolectado, transcurrió entre agosto de 2012 y agosto de 2018.

Para preservar la identidad de las personas que contribuyeron a esta investigación sus nombres son ficticios. Acompañando el nombre se indica si se trata de trabajadores o técnicos de programas de desarrollo rural (t.), personas del pueblo Wichí (w.), personas del pueblo Qom (q.) y/o noindígenas $(n-i)$.

Para escribir las palabras en qom l'aqtaga, haremos uso del alfabeto de Buckwalter y Litwiller de Buckwalter (2013) a menos que se trate de palabras escritas de otro modo en la fuente original, la cual será respetada. Para escribir las palabras en wichí usaremos el vocabulario de Montani (2007) a menos que se trate de palabras escritas de otro modo en la fuente original, la cual será respetada.

\section{Dueños no-humanos y arco iris en la recolección de chaguar y palma}

Zamora (2018, p. 101), reconocido pensador del pueblo Wichí de la provincia del Chaco, habla de la "misión de custodiar la naturaleza" de los dueños no-humanos. Por su parte, Montani (2017, p. 58) apunta que los "dueños" y "sus dependientes" mantienen una "relación asimétrica no coercitiva". Mediante esta relación, nos dice dicho autor, los dueños nohumanos ayudan a que los seres que dependen de ellos se multipliquen, dirigiéndolos en sus movimientos, cuidándolos de los depredadores (mezquinándoselos) y tomando represalias por "los abusos o infracciones que cometen contra ellos los wichi” (p. 58).

Hay dueños no-humanos que se relacionan estrechamente con los vegetales. Montani (2007) y Suárez (2012, p. 153) indican que las Bromeliaceae textiles como la $B$. hieronymi tienen un dueño que se llaman "Jwistes". Suárez (2012, p.153) precisa que cuando las mujeres wichí extraen demasiado chaguar o dañan los "chaguarales" (matorrales de chaguar sobre los que la Jwistes tiene su casa), "la Jwistes 'dueña' se deja ver, asustando a las personas". Asimismo, escribe dicha autora, otras especies vegetales, aunque sin dueño específico, se encuentran bajo el amparo de "Tahyi-Lhele" o "dueño del monte" (p. 166).

Los dueños no-humanos "cuidan", “gobiernan", “protegen" a determinados seres. Para personas del pueblo Qom, Valentín Suárez en Tola y Suárez (2013, p. 65) afirma: "nosotros, cuando vemos el agua o los montes, sabemos que existen unos [seres] de los que dependen esos montes, que los cuidan y velan por ellos [el destacado es nuestro]". Por su parte, el 
pensador del pueblo Qom Orlando Sánchez (2010, p. 76) Ilama a estos seres: "entidades que tienen poder". Uno de ellos es No'ouet que es un ser masculino que "gobierna la naturaleza" (p. 76). Asimismo, Martínez (2012) habla de una entidad específicamente relacionada con la palma cuyo nombre es lagaxadai Ita 'a (madre o dueña de la palma).

La vinculación con estos seres requiere por parte de los humanos al menos de: pedir permiso o emitir plegarias (realizadas generalmente con el pensamiento) para adentrarse al monte; limitar a la necesidad el aprovisionamiento de alimentos $u$ otros elementos del monte; tratar con respeto a las presas animales y los vegetales y evitar la incursión por el monte cuando la persona emite ciertos olores vinculados al ciclo vital (por ejemplo: período menstrual).

Los Arco Iris, que habitan cuerpos de agua como ciénagas, lagunas y cañadas, son particularmente sensibles a ciertos olores. Se manifiestan a causa de la transgresión de períodos de reclusión a respetar, por ejemplo, cuando se está menstruando. Palmer (2013) indica que olores como los emitidos durante el período menstrual desagradan a los Arco Iris a quienes además perturba la combinación de agua con materia orgánica insalubre. Este autor explica que dicha perturbación se debe a que los Arco Iris o Lawo son símbolos de una vitalidad que resulta comprometida con la transgresión de períodos de reclusión como el mencionado antes.

Como protectores del agua y símbolos de vitalidad, los Arco Iris que se manifiestan provocan, por ejemplo, hundimientos de la tierra. En este sentido, el Vocabulario de la lengua qom elaborado por Buckwalter y Litwiller de Buckwalter (2013, p. 172) define al Arco Iris o Quemoxonalo como "la víbora grande que castiga con terremoto si una mujer que menstrúa busca agua”.

Cuando los humanos no cumplen con los requisitos mencionados antes, los dueños no-humanos y los Arco Iris toman represalias. Pueden, por ejemplo, causar enfermedades o provocar cambios en el paisaje (hundimiento o resquebrajamiento de la tierra). Para evitar dichas represalias, las personas se relacionan con estos seres cumpliendo aquellos requisitos y apelando a la compasión de los dueños no-humanos para que les brinden lo que necesitan (por ejemplo: chaguar, hojas de palma y plantas tintóreas).

La predominancia del don en las relaciones entre humanos y nohumanos en la ontología qom es destacada por Tola (2012) al analizar las relaciones entre humanos y dueños de especies animales y vegetales. La autora explica que dichas relaciones "se caracterizan por la deferencia, el cuidado y el respeto que se expresan a través de una actitud de sumisión" (p. 114). En actitud de sumisión, cazador y recolector/a emiten plegarias tratando de despertar la compasión del dueño no-humano para obtener lo que necesitan (TOLA, 2012). Y el encadenamiento sumisión-compasión-don, nos dice Tola (2012), funciona siempre que los humanos se comporten con responsabilidad, respetando una serie de reglas cinegéticas y controlándose a sí mismos. En cambio, cuando los humanos no actúan con respeto y 
autocontrol, es decir sin mesura y con derroche, los dueños pueden atacarlos mediante el castigo, la venganza y el envío de enfermedades (TOLA y SUÁREZ, 2013).

\title{
Domesticación del chaguar
}

Durante el año 2016, Fundación Gran Chaco (ONG) puso en marcha un proyecto de desarrollo rural para trabajar con un colectivo de artesanas wichí de Misión Nueva Pompeya con quienes venían trabajando desde alrededor del año 2012 junto con personas del Programa de Desarrollo de Áreas Rurales (agencia estatal). Este proyecto incluía la plantación de chaguar o chitsaj en los predios de las artesanas interesadas. Buscaban facilitar así el acceso a dicho vegetal por parte de las artesanas, quienes deben recorrer distancias cada vez más prolongadas para recolectarlo. En julio de 2016 conversé con algunas de las mujeres participantes de este proyecto quienes desde hacía poco habían plantado chaguar en sus casas. Graciela (w.) decía lo siguiente:

\begin{abstract}
Antes no plantaba chitsaj porque no había nadie que ayude, no como ahora que hay gente que ayuda a los pobres. [...] Cuando se pone muy sequia el chaguar se seca, necesita agua, tiene poquito hilo, no tiene más fuerza el chaguar porque está muy seca la tierra [...] Podemos regar el chaguar nuestro con agua de represa que viene de lluvia. Arco Iris está en represa cerca de mi casa, nunca se acaba el agua [...] Arco Iris mantiene que haya agua. [...] Chancho come raíz, vizcacha también come raíz porque en esa raíz hay agua por eso come. En plantación no van a entrar los animales porque estamos cuidando que no entren. En el monte nadie cuida, por eso que comen.
\end{abstract}

Revisando lo que explicaba Graciela (w.), la sequía compromete la existencia tanto del chaguar que crece en el monte como del chaguar plantado por ella. Sin embargo, a este último lo cuidaría regándolo con el agua que obtendría de una represa que nunca se seca a causa de que está habitada por un Arco Iris. Además de la sequía, los animales que comen el chaguar también comprometen su existencia. A diferencia de los chitsaj que crecen en el monte, Graciela cuidaría a los plantados para que aquellos animales no los coman. Ahora, mientras el Arco Iris continúa cuidando el agua, ¿dónde están los dueños no-humanos que cuidan el chaguar? ¿por qué se van unos seres mientras otros permanecen? ¿podemos pensar que en el proceso de plantación de chaguar surgen "nuevos dueños" que si bien reemplazan al dueño del chaguar no reemplazan a los cuidadores del agua? ¿estos nuevos dueños son las artesanas que plantan el chaguar o "la gente que ayuda a los pobres", en este caso, miembros de Fundación Gran Chaco? 
Eva (w.) primero plantó unas plantas de alrededor de $50 \mathrm{~cm}$ de alto que no crecían. Luego plantó unas de entre 60 y $70 \mathrm{~cm}$ de alto que estaban creciendo, una de ellas tenía "un hijo". Las había dispuesto contra el alambrado que rodea su casa en el pueblo. Decidió colocarlas de esta manera previendo el caso de que alguno de sus hijos resultara beneficiario de alguna vivienda (la construirían en lo que hoy es el patio de la casa). Me contaba que unos bichitos como piojos comen las raíces del chaguar plantado en su casa, lo cual no ocurre con los que crecen en el monte. Además de no ser atacadas por esos bichitos decía Eva (w.): "las plantas que hay en el campo son lindo no se secan porque están bajo un árbol. Lo que más le gusta [al chaguar] es el duraznillo. Las hojas caen y con ese crecen". Noté que había otras plantas en la casa de Eva (w.): una malva, que es remedio para la tos convulsa y una doca que había traído del campo. La doca (Morrenia adorata) produce unos frutos con los que se puede hacer un dulce que resulta muy parecido al de mamón (Carica papaya). Arenas (2003, p. 262) señala que aquella "es una de las pocas plantas silvestres sembradas" o, de surgir espontáneamente, protegida por parte de los Toba Ñachilamole\#ek y los Wichí-Lhuku'tas del Chaco Central.

Como Eva (w.), Emilce (w.) tenía varias plantas en su casa entre las que se encontraba una ancocha ${ }^{2}$ (planta tintórea). Me contaba que una vez había traído uno de estos vegetales desde orillas del río y plantado en su casa y no había crecido. En cambio, esta planta que ya estaba bastante grande ( 1 metro $50 \mathrm{~cm}$ aproximadamente), Emilce (w.) especulaba que habría crecido a partir de una semilla que alguna vez se le habría caído cuando trajo partes de la planta para teñir chitsaj. Decía: "y ahora cuando hizo frutos, cuando se cae va a haber mucho [plantas de ancocha]". Me mostraba debajo de la ancocha, en unos planteros donde tenía plantas ornamentales, unas plantitas que estaban saliendo y que parecían hijas de aquella. Decía Emilce:

[Ancocha] sólo no más viene, cuando nadie tocó y vivió, viene, no se rompe [...] Yo plantaba chitsaj en el Centro [punto de encuentro frecuente de artesanas y técnicos en El Sauzalito], pero se secó, no sé qué le gusta, o la tierra y cuando estaba en el monte creció bien, igual con tierra seca [en el monte crece hasta con tierra seca]. Antes cuando yo quería ancocha traje chiquito del río, traje y regué todos los días y se secó y ese que no plante salió y creció bien.

Hacía unos meses, promovido por Nélida (t. n-i) y Fermina (t. n-i), habían plantado dos o tres chitsaj en un lugar de encuentro en El Sauzalito conocido de diversas formas como "el Centro", "Fondo Artesanal", "el salón"

\footnotetext{
${ }^{2}$ El nombre criollo es similar al señalado por Montani (2007) como "ancocho". El nombre en wichi que encontramos es diferente al señalado por este autor como samanekw. Suárez y Arenas (2012) coinciden con Montani (2007) en relación al nombre en wichí y varían levemente en relación al nombre criollo (SUÁREZ Y ARENAS lo conocen como "ancoche"). Los tres autores coinciden en la nomenclatura científica: Vallesia glabra.
} 
o "la artesanía". A esos chitsaj se está refiriendo Emilce en el testimonio anterior. Tanto al chitsaj como al plantín de ancocha, Emilce (w.) los plantó y regó. Sin embargo, se secaron. En cambio, la ancocha que "vino sola" (su llegada no respondía a la intención de Emilce (w.)) y que fue regada "creció bien". En relación al chitsaj que se secó, Emilce dice: "no se qué le gusta, o si la tierra". No se secó por falta de agua porque ella lo regaba. En todo caso, se podría haber secado a causa de la composición de la tierra y del ámbito de vida (lo que le gusta al chitsaj). De este modo, por un lado, está el "crecer bien" y "el secarse" y por otro la reproducción de la planta. El crecer bien y el secarse parecen ser cuestiones que quien cuida la planta puede administrar, en cambio, la reproducción excede a la intención de quien la cuida.

Imagen 1: chaguar plantado en vivienda de Eva (w.) (izquierda); doca en casa de Eva (w.) (derecha)
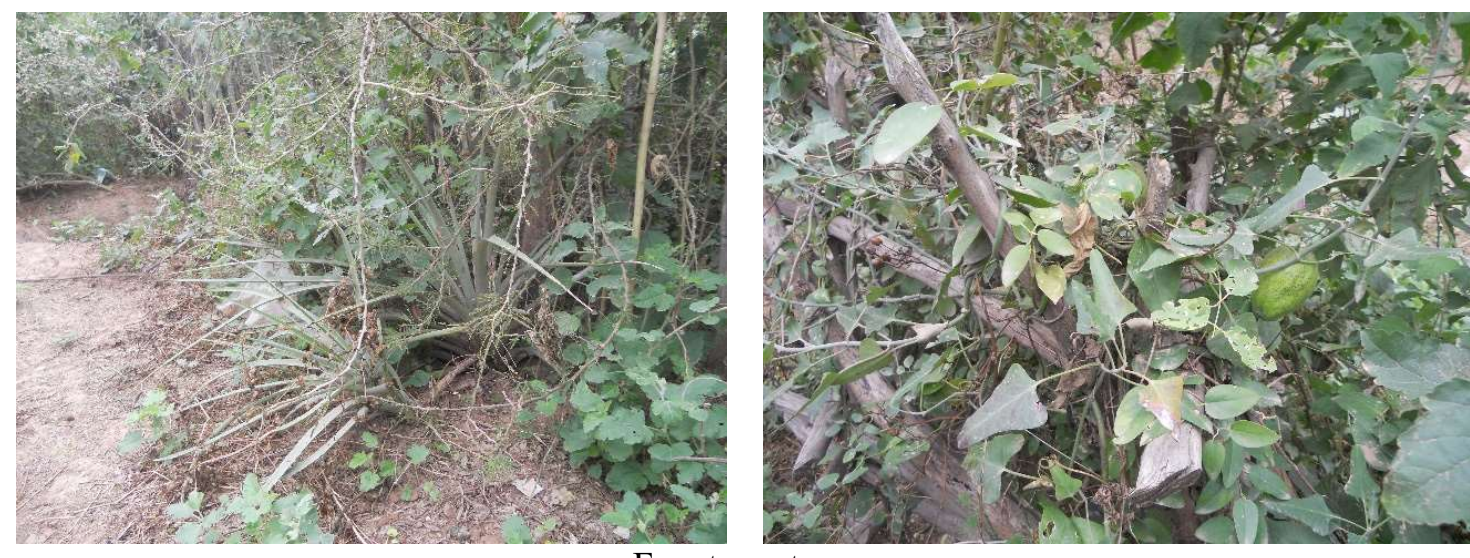

Fuente: autora.

Macarena (w.) me mostró un guayaibí que vive en el patio de su casa. Usa sus frutos para hacer colgantes y/o para decorar carteras hechas con chitsaj. ¿Cómo llegó este arbolito a su casa? pregunté y Macarena (w.) me dijo: "siempre trabajamos artesanía y parece quedo ahí, salen ahí". Alguna vez, cuando se encontraba trabajando con esos frutos, alguno de ellos habría caído al suelo y luego creció la planta. Explicaba Macarena (w.): "salen solo, no hace falta plantar, es como si fuera que es gratis. En Pompeya [Misión Nueva Pompeya] también cerca de la casa crecen esos arbolitos y las mujeres sacan y hacen cortina". Las mujeres no plantan el guayaibí aunque sale cerca de sus casas. Macarena (w.) continuaba explicando:

Es verdad que es gratis. Nosotros sabemos que el Dios hizo todas las cosas que la gente puede saber. Por ejemplo, los remedios vienen del yuyo. También hay planta que hay fruta

\footnotetext{
${ }^{3}$ Cordia americana (MARTÍNEZ, 2012)
} 
Espaço Ameríndio

y sabiendo lo que es bueno y es malo para comer ¿y como saben? [¿cómo saben las personas qué plantas son buenas para comer y cuáles no?] casi lo mismo los animales que nacen y conocen alimento [...] Gallina tiene su pollito, no hace falta que uno le muestre, ellos ya saben el alimento, no hace falta que uno le muestre. [...] Igual que el perro, no habla, no es como nosotros ¿y por qué el perro sabe dónde conseguir remedio? Cuando se siente mal conoce remedio y él no habla [el perro] [...] De Dios viene el pensamiento, no hay otro, nosotros creemos eso [...]

La gratuidad del guayaibí tiene que ver, por un lado, con que fue hecho por Dios y por otro con que de Dios proviene el pensamiento sobre para qué son las plantas. Macarena (w.) cuenta esto mediante diferentes ejemplos que involucran a humanos y no-humanos: las personas que saben qué fruto comer o no desde el nacimiento; el pollito que sin que nadie le muestre sabe que comer y el perro que sabe que yuyo comer cuando está enfermo. ¿Estas plantas existen porque las hizo Dios para cubrir alguna necesidad?

En otra ocasión, conversábamos con Macarena (w.) sobre árboles y heladas, ella contaba:

Si llega la helada no va a tener más frutos, va a quedar
como escaso las chauchas. Si llueve se pierden las flores
[...] La gente antes comía las chauchas. Es alimento de la
gente que no tiene. Tiempo de las chauchas cuando hay
gente junta, hace troja y dejan y guardan sabiendo que no
van a tener que comer. Es como la gente blanca que
cosechan trigo, es casi lo mismo, pero es chauchas. Y si
llego tiempo de poroto ${ }^{4}$ también, es como algarrobo, pero
de otra forma [...] Nosotros no sembramos [algarrobo],
nace solo. Los arboles nacen y se crían solos.

Así como "la gente" del pueblo Wichí junta las chauchas para comer, "la gente blanca" cosecha trigo para comer. Mientras al trigo lo siembran y cuidan las personas, a los algarrobos ${ }^{5}$ no los siembran las personas, sino que nacen y se crían solos. Ese nacer y criarse solos, sin embargo, permanece conectado a las acciones humanas. Macarena (w.) planteaba que la sequía, las catástrofes naturales (como tornados y hundimientos de la

\footnotetext{
${ }^{4}$ Poroto del monte o Capparis retusa (ARENAS, 2003, p. 269). Arenas (2003) indica que esta planta fructifica en verano, recolectándose sus frutos entre enero y febrero. El mismo autor apunta que los frutos son consumidos luego de hervidos.

${ }^{5}$ Algarrobo o Prosopis spp. (ARENAS, 2003, p. 275). Arenas (2003) describe nueve tipos de algarrobos. Este autor afirma que en todo el Gran Chaco sus habitantes consumen las vainas e indica que la época de maduración ocurre entre noviembre y diciembre, antes de las lluvias estivales o la crecida de los cauces hídricos. Asimismo, apunta que las chauchas se consumen y preparan del siguiente modo: frutos frescos; añapeo; harina; panes o bolas.
} 
tierra) y las enfermedades se deben a que "el mundo no está bien". A su vez, ella decía, eso se debe a que "nosotros mismos no estamos bien" dado que: sólo se piensa en la riqueza, en el dinero, que lleva a que las personas se peleen; no hay piedad; las personas se alimentan inadecuadamente, con cosas que conducen a la enfermedad y no se respetan los procesos corporales (restricciones por menstruación y por el fallecimiento de un familiar). Pensando esto en relación con la algarroba, si bien las personas no siembran los árboles proveedores de chauchas, estos crecen en el monte siempre que el accionar humano no conduzca a la sequía.

Por un lado, están los seres que crecen solos junto con su ámbito de vida, como el algarrobo. El respeto por la vida contribuye a la proliferación de ese compuesto. Por otro lado, están los seres que uno cuida para que vivan, como la ancocha. Regar, mantener alejados a los animales que comprometen su existencia, entender lo que le gusta y facilitárselo son maneras de cuidar. En ningún caso se controla la reproducción de dichos seres. Los seres que se crían en el ámbito del hogar, ya sea porque llegaron casualmente las semillas o porque se trasplantó un espécimen (como es el caso de chitsaj), son cuidados para que no se sequen y crezcan. En la medida que no se pretende controlar la reproducción de estos seres, parece más un proceso de semi-domesticación o "mascotización" que de domesticación. La preocupación por la reproducción de esos vegetales no tiene sentido siempre que se respeten las dependencias mutuas entre humanos y nohumanos, lo cual contribuye a la proliferación de seres-ambientes. Ese respeto asegura, entre otras cosas, la provisión de plantines/semillas a trasplantar al hogar para cuidar.

Después están los vegetales como el anco ${ }^{6}$ o la sandía con los cuales se establece otro tipo de relación en términos reproductivos. Arenas (2003) diferencia a las plantas silvestres, que se recolectan, de aquellas enmarcadas en la agricultura. Dicho autor apunta que, tanto entre los wichí como entre los toba, la agricultura habría tenido un papel secundario, siendo las principales fuentes de provisión alimentaria la caza, la pesca y la recolección. En cuanto a la agricultura, los terrenos de cultivo se eligen teniendo en cuenta la humedad, el color negro del suelo y la sombra ("se busca un monte o bosque ralo") (ARENAS, 2003, p. 322). Se prepara el terreno, apunta el mencionado autor, de la siguiente manera: queman la vegetación seca por las heladas; dejan que se humedezca el suelo con las lluvias; siembran las semillas y esperan nuevas lluvias para que las semillas germinen y crezcan. Anteriormente no se usaban cercos, hoy sí son frecuentes a partir de la presencia del ganado en la zona ("voraces depredadores de sembradíos": cerdos, chivas, burros, caballos, vacas) (ARENAS, 2003, p. 324). En relación a las semillas, Arenas $(2003$, p. 325) dice que los wichí "evocan que en tiempos pasados una parte de la cosecha era guardada como semilla para la próxima siembra". El mismo autor afirma que en la actualidad "contar con

\footnotetext{
${ }^{6}$ Curcubita moschata (SCARPA, 2012)

${ }^{7}$ Citrullus lunatus (SCARPA, 2012)
} 
semillas para cultivar es complicado para la gente" ya que estas son depredadas por roedores o se pierden en siembras infructíferas a causa de la falta de lluvia (p. 325). De hecho, apunta Arenas (2003, p. 325): "uno de los argumentos para justificar por qué carecen de sembrados es por la falta de semillas". Muchas personas con quienes conversé decían que en la actualidad no siembran plantas como el anco porque no tienen semillas ${ }^{8}$. Otras señalan que continúan sembrando y que colocan cercos para proteger los sembradíos de los animales depredadores. Ricardo (w.) se encarga de cuidar lechugas y zanahorias que tienen sembradas en el lote. Riega con agua que distribuye la planta potabilizadora. Destina parte de la producción al consumo de su familia y otra parte a vender en comedores y almacenes del pueblo. En el predio también tienen mistol ${ }^{9}$ y chañar ${ }^{10}$ cuyas frutas comen las gallinas que crían. Además, Carmela (w.), mamá de Ricardo, me mostraba otros vegetales que se encuentran en el predio y salieron solos: cedrón; unas plantas con florcitas chiquitas anaranjadas que dice que pueden usarse como remedio para la fiebre y otra planta que se pone sobre los "nacidos" (granos purulentos) para que los ablande y salgan más fácilmente.

Repasando las relaciones entre humanos y vegetales, estos últimos parecen ser de tres tipos:

- Vegetales que crecen solos en el monte: se respeta compuesto ambienteorganismo, este respeto lleva a la regeneración.

- Vegetales que crecen en el ámbito del hogar: se los cuida como si se tratara de mascotas; guardan estrecha relación con los seres que crecen solos en el monte.

- Vegetales que se siembran: se plantan, cuidan, cosechan y luego se guardan las semillas para asegurar la reproducción; no crecen solos en el monte.

\section{Palma, ntegaoaic, batata}

Las palmas crecen en el monte. Tiempo atrás estos vegetales eran procurados principalmente por el lagaxadai Icom o palmito, es decir, por el alimento que proveían. Entre los años 1970 y 1980 esto comienza a cambiar con las personas procurando, antes que el palmito, las hojas de esta palma. Decía Enrique (q.) que en ese tiempo "Dios le ilumino la mente a alguna anciana y empezaron a hacer los canastos". Este cambio se destaca en las palabras de Emilia (q.):

Nuestra cultura hombre y mujer ya saben que no pueden tocar lo que no es alimento [...] En ese entonces nuestra

\footnotetext{
${ }^{8}$ En los años 70, a partir de la promoción de la Dirección del Aborigen, se sembraban hortalizas, vegetales y frutas.

${ }^{9}$ Ziziphus mistol (MONTANI, 2007).

${ }^{10}$ Geoffroea decorticans (ARENAS, 2003).
} 
Espaço Ameríndio

abuela saca el Icom [...]. Ahora tenemos que cuidar las plantas porque estamos trabajando la cestería. A veces sacamos [sólo] para alimentar en el monte. Antes nuestros abuelos traían un montón, una bolsa [de palmito] [...]. Tenemos que cuidar [...] Por una equivocación queman [las palmas], por ejemplo, haces agua caliente, dejas un tizón y ahí se queman [...] Cuando se queman las plantas también se cocina el palmito, ahí agarran las mujeres y comen [...] Tía [Emilce] cuida bien la planta, que no se saque Icom para que no se funda.

Emilia (q.) explica que, si bien antes se aprovechaba el palmito como alimento, por lo cual se sacaban grandes cantidades (aplicando métodos que a veces incluían la quema de la planta), en la actualidad, y en la medida en que se usan las hojas para hacer canastos u otro tipo de trabajos para vender, se "cuida" que no se consuma el palmito para que la planta continúe proveyendo hojas.

La sola recolección de hojas no compromete la existencia de la palma. Es más, la fabricación de las artesanías, con cuya venta se adquieren bienes necesarios para vivir, lleva a algunas familias a restringir el consumo del palmito o lagaxadai Icom dado que esto sí comprometería la continuidad de la existencia de la palma. En este sentido, Amanda (t. q.) decía: "la gente ahora ya tiene que comer, por eso no saca más palmito". Entonces, se produce un reemplazo del tipo: alimento o palmito por alimentos comprados con dinero obtenido del intercambio de artesanía por dinero. Ese reemplazo de alimentos no necesariamente compromete la relación con los dueños nohumanos del monte. Recordemos que estos seres no actúan en perjuicio de cazadores, recolectores y recolectoras si ellas/os obtiene elementos del monte (por ejemplo, alimentos) cuando verdaderamente necesitan. Por lo tanto, que algunas mujeres dejen de sacar palmito para asegurarse la provisión de hojas de palma, no implica que hayan dejado de necesitar alimento. En cambio, continúan satisfaciendo la necesidad de alimentación, aunque de otra manera, a través de la compra de alimentos en almacenes (u otras organizaciones de este tipo) con el dinero adquirido con la venta de las artesanías fabricadas con hojas de palma. Ahora, ¿cómo son los alimentos adquiridos en almacenes en comparación a los alimentos obtenidos del monte?

Además de la palma, otras especies vegetales crecen en el monte. Algunas de las frutas recolectadas, nombradas con frecuencia, son: algarroba o amap, fruta del chañar o tacai, poroto del monte o ntegac, pasacana, tac ala (fruta de un cactus llamado cotaque o qatogole), sachasandía y doca" ${ }^{1}$. Las mujeres con quienes trabajamos consumen estas frutas ocasionalmente o nunca. Carmen (q.) decía que en la actualidad escasean

\footnotetext{
${ }^{11}$ Teniendo en cuenta a Arenas (2003), posiblemente se trate de Prosopis alba, Geoffroea decorticans, Capparis retusa, Harrisia bonplandi, Bromelia serra, Capparis salicifolia y Morrenia adorata, respectivamente.
} 
estas frutas porque la gente "ya tiene que comer", es decir, tiene otros alimentos para comer. No encontramos quien plante estas especies en su casa. Sin embargo, a veces, alguna de ellas crece en el ámbito de la vivienda (analizaremos esto a continuación). Recordaba Amanda (t. q.) que, durante su infancia, junto con sus hermanas, acompañaban a la mamá a buscar frutas del monte. Mientras la mamá recolectaba las frutas (las iba guardando en una bolsa grande), el papá buscaba alguna presa que cazar o algún panal para obtener miel. Volvían luego a la casa. Las mujeres barrían el suelo alrededor de la vivienda y depositaban allí los frutos recolectados para que se sequen al sol, cuidando que no se acerquen gallinas o perros. Después los molían con el mortero. La alimentación de la familia resultaba una combinación de lo recolectado por su madre, lo cazado por su padre y las batatas y mandiocas que sembraban en las inmediaciones del hogar.

Decíamos que algunas de las especies que crecen en el monte también se pueden encontrar en el ámbito de la vivienda. Este es el caso, por ejemplo, del poroto del monte que proviene de la planta llamada ntegacaic. Esmeralda (q.) tiene una de estas plantas en su casa y contaba que estaba allí cuando ella y su familia empezaron a habitar esa vivienda. Amalia (q.) también tiene una de estas plantas en su casa y, al igual que Esmeralda, a pesar de no haberla plantado, la deja vivir allí. En la casa de esta señora también crece una palma que comparte la condición del poroto del monte, es decir, dicha mujer no la plantó, no sabe cómo llegó a su hogar y sin embargo le permite vivir allí. Esto contrasta con el intento fallido de plantar una palma que había hecho el padre de Amanda (t. q.): al poco tiempo de plantado el vegetal murió.

En una condición similar a la de dichas plantas (que crecen normalmente en el monte y que, de surgir en el ámbito de la vivienda, se cuidan) se encuentran las plantas ornamentales que no crecen en el monte. Una de las fuentes de aprovisionamiento de estas últimas es una señora que viene "el día de cobro" de otro lugar y se instala en la cancha del pueblo a vender plantines. Esmeralda (q.) es una de las clientas de esta señora. Otra forma de hacerse de estas plantas es a partir del intercambio de gajos con otras mujeres. Las plantas que se crían de este modo son atendidas, frecuentemente regadas.

Otras plantas son sembradas, por ejemplo: batata, pomelo, naranja, limón, cebolla, maíz, sandía, coreano, mandioca, zapallo, tomate, anco, perejil, lechuga y acelga. Para sembrar se tienen en cuenta los ciclos lunares. Esto también es destacado por Arenas (2003). Algunas familias siembran estas plantas en el ámbito del hogar, otras en "el lote" familiar y otras no siembran en la actualidad, aunque lo hacían tiempo atrás. Carmen (q.) contaba:

[...] llegó el momento que yo me crie más y bueno a la par de mi papa salía a sembrar. Alquilábamos los bueyes de mi tío y empezamos a arar la chacra. Mientras que mi papá cuando iba arando yo metía la semilla de maíz y sembraba 
Espaço Ameríndio

con mi papá. Hasta carpía así, yo carpía [...] Crecía nuestro sembrado [...] Después un tiempo empezábamos a sembrar porque yo veía que algún técnico agropecuario de la escuela no[s] enseñó, entonces le dije a mi papá: "pa ¿por qué no preparamos algún almacigo?". Entre toque y toque me oía él [...] Ese tiempo también empecé a trabajar como empleada doméstica [...] y de ahí veía las plantas [de] lechuga, perejil, zanahoria, aaahhhi le decía: "Dios me de fuerza para que [...] tenga una plantación así".

Carmen (q.) y su padre trabajaban juntos en la chacra. Ella traía información de la escuela y de la casa de una persona no-indígena (allí trabajaba como empleada doméstica) donde veía distintos tipos de plantas sembradas. Destinaban lo que sembraban una parte al consumo de la familia, otra parte a la venta, lo cual les permitía adquirir cosas que necesitaban y una tercera parte lo regalaban a quienes se acercaban al lote a solicitar estos alimentos. Esto último era frecuente. Carmen (q.) destaca que se trataba de un regalo casi obligatorio ya que de no hacerlo corrían el riesgo de que "los maldigan". Esto también era señalado por Isabel (q.), cuya abuela sembraba, entre otros vegetales, pomelo, naranja y limón. Ella se veía obligada a regalar, aunque sea un poquito de la producción, a quienes llegaban de visita. De todos modos, Isabel (q.) sospechaba le habían tirado una maldición a la casa de su abuela, porque pasó de tener animales y plantas de fruta (cítricos) a no tener nada. Ella no se explica por qué le habrían hecho eso al campo, dado que su abuela era "muy generosa" y "le daba fruta a toda la gente que iba y le pedía". Cuentan que muchas personas que se iban a la cosecha de algodón (alrededor del año 1989), a la vuelta solían ir de visita a los lotes de las familias que tenían algo sembrado. A veces cambiaban algo de lo que obtuvieron como pago por la cosecha, por alimentos sembrados. Otras veces las familias con alimentos sembrados les entregaban alimento a quienes habían ido a cosechar a cambio de nada. Amanda (t. q.) decía, en relación a su familia y a otra (que también sembraba sementera baja), que "mantenían a muchas familias". Quienes sembraban "mantenían a muchas familias" en la medida en que muchos llegaban a sus lotes y llevaban "bolsas y bolsas" de los alimentos sembrados por ellos. Arenas (2003) también menciona este tipo de regalos que se entregaban cuando alguien llegaba de visita a la casa, aunque no hace alusión a la cualidad casi obligatoria de estos actos. En cambio, Gordillo (2006) sí lo hace. A partir de su trabajo con los toba del oeste de Formosa, Gordillo (2006, p. 132) indica que la práctica de "llegarse" o de ir a la casa de un potencial dador, parte de la siguiente regla implícita: "todo toba, sobre todo si es de la misma comunidad, tiene derecho a recibir comida". Dicho autor apunta que este tipo de visitas son realizadas con frecuencia por parte de quienes se encuentran en peor situación socioeconómica hacia los que están mejor, entre ellos, quienes producen alimentos a partir de la agricultura y los que cuentan con algún empleo calificado (concejales, agentes sanitarios, 
docentes, empleados administrativos entre otros). Gordillo (2006) señala que se trata de verdaderas presiones para la distribución de alimentos las cuales conllevan acusaciones de mezquindad y casos de brujería. Tola (2012, p.120) afirma que, entre los qom es una costumbre el pedir lo poco que se posee y no querer compartir provoca resentimiento, lo cual puede derivar en una "acción brujeril" y crítica social. Escribe aquel autor en relación con las presiones distributivas hacia empleados calificados:

Muchos de ellos viven la distribución ya no como una
relación desinteresada marcada por "la costumbre", como
postula la ideología toba de la reciprocidad, sino como fruto
de una coerción colectiva. El temor de las sanciones sociales
que resultan de las acusaciones de mezquindad, a que se
hable mal de ellos y sobre todo a ser embrujados está muy
presente en sus referencias sobre la distribución
(GORDILLO, 2006, p. 143).

El principal rasgo de la reciprocidad generalizada, afirma Gordillo (2006, p.142), constituye su carácter de "reguladora de la apropiación colectiva e igualitaria del producto social". En un contexto de incipiente diferenciación social (responde al acceso al empleo calificado), nos dice Gordillo (2006), el carácter coercitivo de la reciprocidad generalizada se ha acentuado. Amanda (t. q.) agrega que además de estar obligado a convidar, hay que hacerlo con mucho cuidado, por ejemplo, en el caso de convidar cierto tipo de miel hay que advertir a las mujeres embarazadas que no la consuman, ya que de hacerlo el hijo podría tener dolor de cabeza muy intenso. Estas advertencias son necesarias incluso si no se tienen vínculos de parentesco con la persona con quien se comparte.

\section{Respeto y regeneración}

Como mencionamos, hay distintos tipos de vegetales con los cuales los humanos establecen distintos tipos de relaciones: los que crecen en el monte (por ejemplo, la palma y el chaguar), los que crecen en el ámbito del hogar (por ejemplo, tintóreas, frutales, ornamentales) y los que se siembran (por ejemplo, batata y anco). Los humanos se relacionan con estos vegetales de la siguiente manera: se respeta el compuesto ambiente-organismo (vegetales que crecen en el monte); se los cuida como si fueran mascotas (vegetales que crecen en el ámbito del hogar) y se plantan, cuidan, cosechan y guardan las semillas (los que se siembran).

Para pensar los cambios en las relaciones entre humanos y vegetales en los casos analizados (principalmente en cuanto a la palma), resulta de sumo interés la investigación de Descola $(1998,2002,2012)$ respecto de las relaciones entre humanos y animales en sociedades amerindias de las regiones tropicales. Este autor señala que en la medida en que "se confieren 
propiedades culturales a los animales", las relaciones que se establecen entre humanos y animales son relaciones de persona a persona o sociales (DESCOLA, 1998, p. 35) ${ }^{12}$. Estas relaciones responden a un cuadro general de alianza contractual que diferencia entre afinidad y consanguinidad de modo tal que el animal que se caza se presenta como un alter ego (estos animales son considerados afines por parte de los humanos) y el animal que se amansa se presenta como "demasiado idéntico a sí para ser comido" (estos animales son considerados consanguíneos por parte de los humanos) (p. 36 y 37). En relación a esto último, Descola (2012) precisa que si bien personas de dichas sociedades tienen gran experiencia en la crianza de animales en semi-cautiverio, no sólo no se les da muerte, sino que además no se intenta su reproducción en cautiverio. El autor explica que esto es así por diversos motivos, entre ellos, que dichos animales tienen amos o espíritus que los cuidan/crían/protegen. Descola (2002, p.106) puntualiza que la relación de los animales con dichos amos es en sí misma concebida como una relación de domesticación: "[el amo] los conserva en su casa o en un cercado, los protege de predadores humanos, y de ellos se alimenta cuando es necesario". En definitiva, ni los animales que se cazan ni los animales que se amansan son domesticados por los humanos. Entonces, el rechazo a la técnica de domesticación:

\begin{abstract}
$[\mathrm{N}] \mathrm{o}$ es [...] tanto el producto de una decisión consciente que millares de pueblos han tomado en forma independiente, sino consecuencia de la imposibilidad de estos en cuanto a transformar su esquema de relación con el animal, generalizando respecto de ciertas especies una actitud privativa de los no-humanos y que el amansamiento restringe a algunos individuos (DESCOLA, 2012, p. 549).
\end{abstract}

En base a dichas relaciones, vemos que Descola (2012) distingue tres tipos de animales: los que se crían en la selva o silvestres; los que se amansan en el hogar o que se crían en semi-cautiverio y los que se crían en cautiverio. En cuanto a los animales que se crían en el hogar, Carneiro da Cunha (2017) equipara esta práctica y la de tratar a las plantas de guaraná como mascotas o animales de estimación por parte de los Sateré Mawé. La diferenciación efectuada por Descola (2012) respecto de los animales y la puntualización de Carneiro da Cunha (2017) respecto del guaraná son similares a los tres tipos de vegetales señalados en el primer párrafo de este apartado (los que crecen en el monte o son silvestres; los que crecen en el ámbito del hogar como mascotas y los que se siembran).

En el caso de la palma, vimos que, en los últimos años, y en relación con la posibilidad de vender trabajos realizados con las hojas de este vegetal, se pasó de buscar la palma principalmente por el palmito a buscarla

\footnotetext{
12 "Diferentemente do dualismo moderno que distribui humanos e não-humanos em dois domínios ontológicos mais ou menos estanques, as cosmologías amazônicas estabelecem uma diferença de grau, não de natureza, entre os homens, as plantas e os animais" (DESCOLA, 1998, p.25).
} 
especialmente por las hojas. Si bien estos vegetales no se siembran, pasaron a cuidarse, priorizando la recolección de hojas a la recolección del palmito. Se encontrarían así a medio camino entre su crecimiento en el monte y en el ámbito del hogar, ya que, si bien se cuidan, en el sentido que se protege que no se saque el palmito (lo que podría arriesgar la existencia de la palma), siguen habitando espacios alejados de la vivienda familiar y no se riegan.

El cambio antes mencionado respecto de la palma fue dándose de la mano de cambios en la relación con los dueños no-humanos. Tiempo atrás, cuando la necesidad de alimentación era compatible con la quema de la palma para obtener el palmito, los dueños no-humanos no tomaban represalias contra quienes procedían de este modo. En cambio, hoy, que es posible hacerse de alimento sin quemar a la palma (de hecho, al quemarla se complica el acceso al sustento ya que las recolectoras/artesanas pierden el flujo de hojas para fabricar trabajos para vender), los dueños no-humanos pueden actuar en perjuicio de quien lo hace.

En el caso del chaguar, también se produjo un reemplazo similar al de la palma: las personas pasaron de buscar dichas bromelias por el alimento que proveían a buscarlas principalmente por la fibra de sus hojas. Ahora, a partir de la posibilidad de mercantilizar los trabajos y de las propuestas de técnicos de desarrollo del Estado y de la ONG, las recolectoras-artesanas comenzaron a "plantar" chaguar en el ámbito de su hogar. Aunque los técnicos consideran que se trata de siembra, las mujeres que se interesaron por este emprendimiento se relacionan con estos vegetales como si se tratara de mascotas (se ocupan de que no se sequen y de que crezcan, no se ocupan de su reproducción) en vez de tratarlos como vegetales que se siembran (entre otras cuestiones, requiere ocuparse de su reproducción). En relación a los dueños no-humanos, como decíamos antes, es posible que se hayan retirado a otros lugares, lo cual se vincula con las distancias cada vez más prologadas a recorrer para encontrar chaguar. Sin embargo, que se hayan alejado no implica que dejen de existir por lo que no se trataría del reemplazo de dueños no-humanos por dueños humanos.

Schiavoni (2018a) analiza el modo en que la yerba mate pasó de recolectarse a domesticarse: en su condición silvestre, en vez de estar reunidas en grandes agrupaciones, las plantas de yerba se encontraban en pequeñas manchas diseminadas por el monte, lo cual era considerado como un problema por parte de los comisionados de agricultura del gobierno nacional; a fines del siglo XIX la multiplicación de la yerba mate se basaba en trasplantes de mudas silvestres del monte; la promoción de este cultivo por parte del Estado fue Ilevando a organizarlo en un orden rectilíneo y a realizar la multiplicación con semillas, lo cual se generaliza en las primeras décadas del siglo XX. Este proceso hacia la domesticación fue dándose a partir de la influencia del Estado, influencia basada, nos dice Schiavoni (2018a), en una lógica que separa la tierra de la naturaleza por y para la medición y el control. En cuanto a la medición, la multiplicación de la yerba a partir de semillas las independiza de sus parientes silvestres, "convirtiendo la extensión en hectáreas, en el modo estándar de estimación" (p. 9). El 
estímulo a la plantación de chaguar sigue una trayectoria similar a la de la yerba mate en la medida en que se busca independizar el cultivo de estas plantas del monte. Esto tiene que ver con la medición, la cual se ve facilitada con el cultivo que disminuye la variabilidad asociada a la recolección (se trabaja con los aportes de humanos y no-humanos, por ejemplo, dueños y vegetales). Sin embargo, la variabilidad encuentra la forma de meterse en el plan, dejándolo a medio camino entre el monte y el cultivo: las recolectorasartesanas no sólo no se ocupan de la reproducción de estas plantas, sino que están muy lejos de ordenar la plantación en base a la practicidad para la cosecha (el orden que eligen se debe más a cuestiones del uso del espacio por la familia). En el caso de la palma, los agentes de fomento artesanal no se involucraron con propuestas de plantación de este vegetal, en cambio, las mujeres le dan el espacio físico y temporal para que se reproduzcan, para que se regenere el entramado vital.

Los vegetales sembrados traen consigo las presiones que sufren quienes los siembran por parte de quienes no lo hacen y necesitan los alimentos. Las buenas costumbres en cuanto a la distribución de alimentos son descriptas por el mito "Lucero y el hijo de Búho" (MADRES CUIDADORAS DE LA CULTURA QOM, 2009). Las autoras de este libro indican que Chi ishe o Lucero demuestra ser "un ser superior, tierno, compasivo y respetuoso de la libertad de los demás" que usa sus poderes para conseguir alimentos fuera de estación y distribuirlos sin que se acaben, incluso con "quienes hablan mal de ella" (p. 93). Es así como, en la siembra, se espera, de quienes obtienen alimentos, que los compartan con quienes no los tienen y los necesitan. La falta de respeto a dicha premisa acarrea conflictos. Como mencionábamos, Gordillo (2006) destaca la intensificación, en los últimos años, de las presiones distributivas de quienes menos tienen hacia quienes tienen más. Decíamos también que tanto dicho autor como Tola (2012) señalaban que dichas presiones pueden derivar en conflictos que se manifiestan en ataques brujeriles. Tola (2012) describe el modo en que se producen estos ataques e indica que quienes lo hacen (las brujas), pueden adquirir este poder de la madre de las brujas que habita en el monte. Adquirido el poder, la bruja "debe cumplir siempre con las demandas de quien se lo otorgó" (p. 194).

De la persona que siembra se espera que, movida por la compasión ante la necesidad, comparta el alimento con quien no tiene y lo solicita. Si quien siembra no se compadece y entrega alimento a quien necesita, es pasible de sufrir ataques brujeriles que, como veíamos, requieren de la intervención de dueños no-humanos (la madre de las brujas o conaxanaxae que entrega este poder). Pareciera que quienes siembran son como los dueños no-humanos, movidos a compartir a partir de sentir compasión por el otro necesitado. Sin embargo, los humanos no toman represalias contra los dueños no-humanos. Entonces, la siembra se solapa con la existencia de los dueños no-humanos quienes continúan regulando la relación que deviene del encadenamiento necesidad-compasión-don. De esta manera, 
quienes siembran parecen más arrendatarios que dueños, lo cual nos lleva a revisar las relaciones en los intercambios de dones.

A diferencia del intercambio de mercancías, donde, dice Gregory (2015) siguiendo a Marx, se intercambian cosas alienables entre actores que se encuentran en estado de independencia recíproca (siendo la alienación la transferencia de propiedad privada), en el intercambio de dones se cambian cosas inalienables entre personas que se encuentran en dependencia reciproca. Las cosas en el contexto del don no son alienadas, dice Mauss en Gregory (2015), porque no son ni vendidas ni cedidas sino prestadas. Es decir que porque son prestadas y devueltas las cosas son inalienables y ¿qué hace que sean devueltas? El hau dice Mauss, la dependencia recíproca dice Gregory. Por su parte, Godelier (1998, p. 75) plantea que en la circulación de don y contra don no hay devolución sino "re-donar o donar nuevamente". Para que haya devolución la cosa donada debería separarse del donante y este no es el caso. Es decir que, explica dicho autor, no hay alienación "porque la «cosa» donada no se ha separado, no se ha escindido completamente del que la dona. La cosa ha sido donada, sin ser verdaderamente «alienada» de quien la dona. Así, la cosa donada arrastra consigo algo que forma parte del ser, de la identidad de quien la dona" ( $p$. 67). Este arrastre de partes de las personas lleva a Godelier a señalar que en el intercambio de dones una persona ocupa el lugar de otra, y esta sustitución es productiva en términos de alianzas establecidas. La transacción no resulta en que cada propietario se vuelva dueño de la cosa cambiada, como ocurre en los intercambios mercantiles. En cambio, en una "economía y moral del don" como la cosa donada no se encuentra alienada "quien la dona continúa conservando derechos sobre lo que ha donado, consiguiendo con ello una serie de «ventajas»" (GODELIER, 1998, p. 68).

Mientras Mauss (1990) interpreta que la cosa es devuelta porque el hau, al que traduce como espíritu, anima la cosa y hace que esta quiera volver a su lugar de origen; Godelier (1998) interpreta que esta fuerza, que hace que la cosa sea devuelta, consiste en la relación que sigue vinculando la cosa donada con la persona que la dona. De esta manera, la cosa no se desliga de la persona (física y/o moral) que la dona, y su presencia es esa fuerza, la fuerza de los derechos "que sigue ejerciendo sobre la cosa y, a través de ella, sobre aquél a quien la dona y que la acepta" (GODELIER, 1998, p. 70). En otras palabras, los derechos sobre la cosa que tiene el donante obligan al donatario a hacer la devolución/contra don. Al recibir la cosa devuelta, el donatario (antes donante) queda ahora comprometido a devolver y así sucesivamente. Esto se expande abarcando a más personas, a colectividades, de manera tal que todos empiezan/terminan atados por las deudas, dependiendo unos de otros para vivir. En el caso analizado, las dependencias recíprocas se dan entre humanos (quién siembra y quien necesita los alimentos) y entre humanos y dueños no-humanos. Las vinculaciones se basan en el encadenamiento necesidad-compasión-don siendo los dueños no-humanos los invocados para regularlo. 
Podríamos pensar que la devolución al don se produce con el respeto para la regeneración. Sin embargo, mientras la devolución, basada en una noción de stock, lleva a reemplazar una cosa por otra, el respeto para la regeneración conduce a la creación de seres, creación que excede intención y accionar humanos. Entonces, el respeto para la regeneración no es la devolución al don sino la condición para que se produzca. Inspirado en los entendimientos de personas que viven de la jardinería, la labranza de la tierra y la administración de ganado en América del Sur, Melanesia y África Occidental, Ingold (2002, p. 86) destaca las "condiciones para el desarrollo" en el crecimiento de plantas y la crianza de niños y animales. Dichas condiciones, que se aplican tanto para la recolección como para el cultivo, no son provistas sólo por los humanos, quienes, al igual que otros seres, "play their parte [...] in the world's transformation of itself" (p. 87). La adecuación para la convivencia que realizan otros seres, además del humano, también es subrayada por Carneiro da Cunha (2017). Adecuación y seres que son ignorados, apunta dicha autora, cuando la ocupación humana es de tipo colonial.

El respeto para la regeneración, a su vez, requiere de espacio y tiempo para que los seres puedan ser y hacer. Respecto del espacio, Schiavoni (2018b, p. 316) destaca el "rol decisivo" que juega en la interacción espontánea de una variedad de maíz (caianão) sembrada por campesinos itinerantes del departamento de San Pedro (provincia de Misiones). En cuanto al tiempo, Mauss (1990) indica que la distancia temporal entre el dar y el devolver es necesaria para que florezca la relación. No se trata de cualquier tipo de distancia temporal porque tanto si es muy corto o largo el plazo de devolución, el intercambio corre el riego de ser despreciado y luego la relación no progresa (MAUSS, 1990). Aunque no precisamente teniendo en cuenta la dimensión temporal de las transacciones, Mauss apunta que clanes, generaciones y sexos en las sociedades reguladas por las obligaciones de dar, recibir y devolver, están en constante estado de "fermentación económica" (MAUSS, 1990, p. 72). ¿Por qué habla de fermentación? Pensando en la fermentación de uvas para fabricar vino, si el proceso se interrumpe antes de tiempo o si se prolonga demasiado no se obtendrá el líquido deseado. En el caso del intercambio de dones pasa algo similar. Si la distancia entre el momento del dar y el de la devolución no es la adecuada, la relación no logra fermentar.

El respeto para la regeneración brinda distancia temporal y espacial, lo cual no sólo transforma las relaciones entre humanos sino también entre humanos y no-humanos (dueños y vegetales), amplificando la capacidad de creación.

\section{Conclusión}

El modo en que se relacionan artesanas, técnicos de programas de desarrollo rural, dueños no-humanos y vegetales que proveen fibras con las 
que se tejen artesanías destinadas principalmente a la venta, se expresa en la siguiente tipificación de vegetales:

- Vegetales que crecen en el monte, como la palma y el chaguar, cuyo crecimiento requiere que se respete el compuesto ambiente-organismo;

- Vegetales que crecen en el ámbito del hogar, como algunas plantas tintóreas, frutales y ornamentales, que se cuidan como mascotas para que crezcan;

- Vegetales que se siembran, como el anco o la batata, que se plantan, cuidan, cosechan y guardan las semillas para que crezcan y se reproduzcan.

Al comparar el modo en que se relacionan técnicos y artesanasrecolectoras con chaguar y palma vemos que, mientras que las propuestas de los técnicos para el resguardo del chaguar vienen por el lado del control de su reproducción y ubicación espacial, el resguardo de la palma por parte de las recolectoras-artesanas viene por el lado del respeto, del dar tiempo/lugar para la regeneración. En otras palabras, si en el caso de la domesticación prima el hacer en el caso de la recolección prima el dejar ser/hacer, permitiendo que otros se expresen.

Además de los vegetales que crecen en el monte, tanto los vegetales que crecen en el ámbito del hogar como los que se siembran guardan relación con los dueños no-humanos. Estas vinculaciones se basan en el encadenamiento necesidad-compasión-don. En el caso de los vegetales sembrados, se puede vislumbrar dicho encadenamiento y el efecto de los dueños no-humanos (en particular, la madre de las brujas) al considerar las represalias que podrían recaer sobre quienes siembran los alimentos y no los comparten con quienes no siembran, aunque los necesitan.

En todos estos casos, la presencia de los dueños no-humanos se relaciona con espacio y tiempo requeridos para la regeneración de los seres. Su presencia invisible, aunque visible por sus efectos sobre cuerpos y paisajes, recuerda que no son sólo los humanos quienes participan del crecimiento de los vegetales. Las dependencias recíprocas entre humanos y entre humanos y no-humanos del mismo habitar un tiempo y lugar transforman las relaciones entre los habitantes y crean algo nuevo, muchas veces imprevisto.

Además de imprevistos, los efectos de la habitación pueden ocurrir a la vez y en paralelo. En este sentido, veíamos, respecto de la plantación del chaguar, que para los técnicos los vegetales criados en estas condiciones constituyen vegetales sembrados. Sin embargo, para las artesanas involucradas se trata de vegetales como mascotas. De este modo, conviven, aunque ignorándose, dos modos de relacionarse con vegetales. 


\section{Referencias bibliográficas}

ARENAS, Pastor. Etnografía y alimentación entre los Toba-Ñachilamole\#ek y WichíLhuku`tas del Chaco central (Argentina). Buenos Aires: Autor, 2003.

BUCKWALTER, Alberto S. y LITWILLER de Buckwalter, Lois. Vocabulario toba. 2013. Disponível em: http://www.chacoindigena.net/Materiales files/Vocabulario\%20Toba.pdf.

CARNEIRO DA CUNHA, Manuela. ¿Domesticación o anti-domesticación en Amazonia indígena? Conferencia Reunión de Antropología del Mercosur 06/12, 2017. Disponível em: https://www.youtube.com/watch?v=1ljF24dYb-c

DESCOLA, Philippe. Estrutura ou sentimento: a relação com o animal na Amazônia. Revista Mana, 4(1), p. 23-45, 1998.

DESCOLA, Philippe. Genealogia de objetos e antropologia da objetivação. Revista Horizontes Antropológicos, Porto Alegre, ano 8, n. 18, p. 93-112, 2002.

DESCOLA, Philippe. Más allá de naturaleza y cultura. Buenos Aires: Amorrortu, 2012.

GORDILlO, Gastón. En el Gran Chaco: Antropologías e historias. Buenos Aires: Prometeo Libros, 2006.

GREGORY, Chris A. The competing theories. In: Gifts and Commodities. Chicago: The University of Chicago Press, 2015.

INGOLD, Tim. The perception of the environment. Essays on livelihood, dwelling and skill. Londres: Routledge, 2002.

Madres Cuidadoras de la Cultura Qom. Relatos Qom. Córdoba: Copiar, 2009.

MARTÍNEZ, Gustavo J. Recolección, disponibilidad y uso de plantas en la actividad artesanal de comunidades tobas (qom) del Chaco Central (Argentina). In: ARENAS, Pastor et al. (eds.). Etnobotánica en zonas áridas y semiáridas del Cono Sur de Sudamérica. Buenos Aires: Edición literaria a cargo de Pastor Arenas, Consejo Nacional de Investigaciones Científicas y Técnicas [CONICET], 2012. p. 195-224.

MAUSS, Marcel. The gift. The form and reason for exchange in archaic societies. Routledge: New York, 1990.

MONTANI, Rodrigo. EI mundo de las cosas entre los wichis del Gran Chaco. Un estudio etnolingüístico. Cochabamba: Itinerarios Editorial, 2017.

MONTANI, Rodrigo. Vocabulario wichí del arte textil: Entre la lexicografía y la etnografía. Revista Mundo de antes, 5, p. 41-72, 2007. 
Espaço Ameríndio

PALMER, John H. La buena voluntad wichí: una espiritualidad indígena. Las Lomitas: Asociación para la Promoción de la Cultura y el Desarrollo, 2013.

SÁNCHEZ, Orlando. Rasgos culturales tobas. Resistencia: Librería La Paz, 2010.

SCARPA, Gustavo F. Palos, yuyos, pencas, bejucos y pastos: Los nombres de las plantas y su clasificación etnobotánica por los criollos del Chaco Semiárido Norte (NE Salta - W Formosa). In: ARENAS, Pastor et al. (eds.). Etnobotánica en zonas áridas y semiáridas del Cono Sur de Sudamérica. Buenos Aires: Edición literaria a cargo de Pastor Arenas, Consejo Nacional de Investigaciones Científicas y Técnicas [CONICET], 2012. p. 117-144. SCHIAVONI, Gabriela O. De las familias criollas a las lignées purificadas. Analogías entre vegetales y humanos. Revista Anuário Antropológico, Brasília, UnB, v. 43, n. 2, p. 309$334,2018 b$.

SCHIAVONI, Gabriela O. Habitar y medir el territorio. Los vínculos con la tierra de colonos, ocupantes y guaraníes en Misiones. Revista Corpus, Vol. 8, No 1, p. 1-25, 2018 a.

SUÁREZ, María E. Espíritus vinculados con el bosque y sus plantas en el mundo de los wichís del Chaco Semiárido salteño, Argentina. In: ARENAS, Pastor et al. (eds.). Etnobotánica en zonas áridas y semiáridas del Cono Sur de Sudamérica. Buenos Aires: Edición literaria a cargo de Pastor Arenas, Consejo Nacional de Investigaciones Científicas y Técnicas [CONICET], 2012. p. 145-177.

SUÁREZ, María E. y ARENAS, Pastor. Plantas y hongos tintóreos de los wichís del Gran Chaco. Revista Bol. Soc. Argent. Bot. 47 (1-2), p. 275-283, 2012.

TOLA, Florencia C. y SUÁREZ, Valentín. Diálogo sobre los existentes de un entorno superpoblado en el contexto de la marisca y la reivindicación política del territorio. In: TOLA, Florencia C.; MEDRANO, Celeste; CARDIN, Lorena (eds.). Gran Chaco. Ontologías, poder, afectividad. Buenos Aires: Asociación Civil Rumbo Sur, 2013. p. 45-76.

TOLA, Florencia C. Yo no estoy solo en mi cuerpo: cuerpos-personas múltiples entre los tobas del Chaco argentino. Buenos Aires: Biblos, 2012.

ZAMORA, Leckott. Ecos de la resistencia. Resistencia: Con Texto Libros, 2018.

Recebido em: 20/05/2019* Aprovado em: 07/11/2019* Publicado em: 30/12/2019

PERRET, Myriam Fernanda. Tiempo y espacio para la regeneración de vegetales en tres localidades de la provincia de Chaco, Argentina. Espaço Ameríndio, Porto Alegre, v. 13, n. 2, p. 161-183, jul./dez. 2019. 